\title{
PAPERS
}

\section{Does routine ultrasound scanning improve outcome in pregnancy? Meta-analysis of various outcome measures}

\author{
Heiner C Bucher, Johannes G Schmidt
}

\begin{abstract}
Objective-To evaluate the effectiveness of routine ultrasound scanning in pregnancy by a metaanalysis of various outcome measures.

Design-Meta-analysis of randomised controlled trials evaluating the effect of routine ultrasound scanning on perinatal mortality and morbidity. Live birth rate (that is, live births per pregnancy) is included as a measure of pregnancy outcome in addition to the conventional perinatal mortality.

Subjects-15935 pregnancies (7992 in which routine ultrasound scanning was used and 7943 controls with selective scanning) from four randomised controlled trials.
\end{abstract}

Main outcome measures-Perinatal mortality, live birth rate, rate of miscarriage, Apgar score $<7$ at 1 minute, and number of induced labours.

Results-The live birth rate was identical in both screening and control groups (odds ratio $=0.99 ; 95 \%$ confidence interval 0.88 to 1.12 ) although the perinatal mortality was significantly lower in the group who had routine ultrasonography $(0.64,0.43$ to 0.97$)$. Differences in perinatal morbidity between the two groups as measured by the proportion of newborn babies with Apgar score $<7$ at 1 minute were not significant $(1.05 ; 0.93$ to 1.19$)$.

Conclusion-Routine ultrasound scanning does not improve the outcome of pregnancy in terms of an increased number of live births or of reduced perinatal morbidity. Routine ultrasound scanning may be effective and useful as a screening for malformation. Its use for this purpose, however, should be made explicit and take into account the risk of false positive diagnosis in addition to ethical issues.

\section{Introduction}

Ultrasound examinations for pregnant women are now routinely performed in many countries. One stage ultrasound screening is recommended by the Royal College of Obstetricians and Gynaecologists in the United Kingdom,' a two stage screening has been advocated in Germany, ${ }^{2}$ and a three stage screening in France. ${ }^{3}$ The United States preventive services task force, however, does not recommend screening. ${ }^{4}$ What is the evidence that routine ultrasound scanning may be beneficial for the outcome of pregnancy?

Ultrasonography in pregnancy improves the dating of gestational age, ${ }^{5}$ which may lead to a reduction in the number of induced labours in cases in which the gestation is overestimated. ${ }^{67}$ It is the most accurate means of detecting retardation in fetal growth ${ }^{8}$ and multiple gestations, 9 and it is effective in detecting severe malformations. ${ }^{10}$ In spite of these achievements, however, the important question is whether routine ultrasonography improves the outcome of pregnancy and whether it shows an overall net benefit. The early detection of fetal growth retardation, for example, may be of some theoretical value by allowing early planned delivery, although there is lack of truly effective therapeutic means to treat growth retardation." 12 Evidence from randomised controlled trials, however, suggests that the sonographic identification of fetal growth retardation does not improve the outcome of pregnancy despite increased medical attention. ${ }^{1314}$ The prediction of the date of delivery through ultrasound scanning is certainly more accurate than with the menstrual history. Whether an improved dating of gestational age to prevent "overdue" deliveries will effectively decrease birth complications, however, remains debatable. Complications during spontaneous delivery increase progressively from 37 weeks' gestation. ${ }^{15}$ Thus, it may be difficult to define with confidence after which week a delivery is overdue, and it cannot be assumed a priori that the induction of labour, in the absence of other complications, will improve the outcome. Inducing labour in such cases compared with serial monitoring (fetal kicks, volume of amniotic fluid, tests to detect fetal stress) does not seem to change perinatal mortality and morbidity, though the rate of caesarean section may be slightly reduced. ${ }^{16} 17$

Studies of the diagnostic performance of ultrasonography may provide valuable information. Only randomised controlled trials which include measures of the eventual outcome of pregnancy as endpoints, however, are qualified to answer the crucial question of whether routine ultrasonography is truly beneficial or not.

\section{MEASURES OF PREGNANCY OUTCOME}

Perinatal mortality is often used to assess the outcome of pregnancy. The detectability of malformations by ultrasonography, however, raises the question of the validity of perinatal mortality as a measure of outcome when routine ultrasound scanning has been used. Fetal malformations are a major contributor to perinatal mortality. In the absence of ultrasonography a malformed fetus unable to survive the extrauterine state is counted as a perinatal death, whereas the same fetus would be considered as an antenatal case of early abortion if detected by ultrasonography. Induced abortions because of malformations detected by ultrasonograph may therefore bias the perinatal mortality because induced abortions decrease the numerator but leave the denominator of perinatal mortality basically unchanged. Therefore, the rate of live births - that is, the number of live births per pregnancy-may be a better measure of the outcome of pregnancy. The purpose of antenatal care is to lead a maximum number of pregnancies to live birth by preventing harm and managing complications during pregnancy and delivery. Whereas the conventional perinatal mortality does not consider possible losses of pregnancies before delivery, the live birth 
rate may be considered a measure of the overall pregnancy outcome.

The present study includes an analysis of the conventional perinatal mortality, the live birth rate, and the Apgar score as well as the rate of induced labour in the randomised controlled trials published so far. Some unpublished data were obtained from the authors of these trials. A meta-analysis was performed to maximise statistical power to detect true differences in these measures of pregnancy outcome and because individual studies were too small to be generalisable. ${ }^{18}$ This study is therefore different from existing metaanalyse ${ }^{19}$ in that it contains the live birth rate as a new, unconventional but important outcome measure.

\section{Methods \\ SELECTION AND DESCRIPTION OF STUDIES}

Randomised controlled trials were identified by a Medline literature search and by a comparison with recent review articles on ultrasound screening in pregnancy. ${ }^{1920} \mathrm{~A}$ trial was included if the following criteria were met. Firstly, the study had to compare routine ultrasound scanning with selective ultrasound scanning, which means that randomisation had to occur before the first scan: Secondly, perinatal mortality (that is, the number of deliveries and the number of perinatal deaths) and the number of pregnancies had to be reported. Eight randomised controlled trials of ultrasonography in pregnancy were identified. The trial by Bennett et al reported perinatal mortality but all pregnant women had an ultrasound scan. ${ }^{21}$ The results of this scan were made available in the study group but not in the control group except in case of a clinical problem. Thus, it did not truly compare routine with selective ultrasound and was excluded from our analysis according to the first criterion, as were the studies of Secher $e t a l^{14}$ and Neilson et al. ${ }^{22}$ One trial did not meet the second

TABLE I-Randomised controlled trials of routine versus selective ultrasound scanning in pregnancy

\begin{tabular}{|c|c|c|c|c|c|}
\hline \multirow[b]{2}{*}{ Trial } & \multirow[b]{2}{*}{$\begin{array}{l}\text { No of } \\
\text { women } \\
\text { recruited }\end{array}$} & \multirow[b]{2}{*}{ Subject selection } & \multirow[b]{2}{*}{$\begin{array}{l}\text { Scanning regimen } \\
\text { (gestation at scan) }\end{array}$} & \multicolumn{2}{|c|}{$\begin{array}{l}\text { Percentage of pregnancies } \\
\text { having ultrasound }\end{array}$} \\
\hline & & & & $\begin{array}{l}\text { Cases } \\
\text { (routine } \\
\text { ultrasound) }\end{array}$ & $\begin{array}{l}\text { Controls } \\
\text { (selective } \\
\text { ultrasound) }\end{array}$ \\
\hline Helsinki ${ }^{24}$ & 9310 & $\begin{array}{l}\text { All women at first antenatal visit at } \\
\text { maternal health centres }\end{array}$ & $\begin{array}{l}\text { One stage (16-20 } \\
\text { weeks) }\end{array}$ & $86 \cdot 8$ & $77 \cdot 0$ \\
\hline Trondheim ${ }^{25}$ & 1017 & $\begin{array}{l}\text { All women at first antenatal visit at } \\
\text { general practice }\end{array}$ & $\begin{array}{l}\text { Two stage (19 and } 32 \\
\text { weeks) }\end{array}$ & $89 \cdot 4$ & $10 \cdot 2$ \\
\hline Stockholm ${ }^{7}$ & 4997 & $\begin{array}{l}\text { Women without clinical indication for } \\
\text { first ultrasound at first visit in three } \\
\text { hospitals }\end{array}$ & One stage ( 15 weeks) & $64 \cdot 2$ & $31 \cdot 8$ \\
\hline Missouri $^{26}$ & 915 & $\begin{array}{l}\text { Women without clinical indication for } \\
\text { first ultrasound at first visit at two } \\
\text { hospitals }\end{array}$ & $\begin{array}{l}\text { One stage (10-12 (up } \\
\text { to } 18 \text { ) weeks) }\end{array}$ & $83 \cdot 8$ & $23 \cdot 9$ \\
\hline
\end{tabular}

TABLE II-Randomised controlled trials of routine versus selective ultrasound scanning in pregnancy: development of pregnancies, perinatal deaths, and live births

\begin{tabular}{|c|c|c|c|c|c|c|c|c|}
\hline \multirow[b]{2}{*}{ Detail } & \multicolumn{2}{|c|}{ Helsinki $^{24}$} & \multicolumn{2}{|c|}{ Trondheim ${ }^{25}$} & \multicolumn{2}{|c|}{ Stockholm ${ }^{7}$} & \multicolumn{2}{|c|}{ Missouri $^{26}$} \\
\hline & Cases & Controls & Cases & Controls & Cases & Controls & Cases & Controls \\
\hline Women recruited & \multicolumn{2}{|c|}{9310} & \multicolumn{2}{|c|}{1017} & \multicolumn{2}{|c|}{4997} & \multicolumn{2}{|c|}{915} \\
\hline Lost/not available & & & & 8 & & 4 & & \\
\hline Randomised & 4691 & 4619 & 510 & 499 & 2482 & 2511 & 459 & 456 \\
\hline Not pregnant & 15 & 2 & & & & & & \\
\hline Legal abortion & 26 & 21 & & & 6 & 3 & & \\
\hline Refused & & & & & & & 11 & 5 \\
\hline Lost to follow up & 1 & 3 & 1 & 2 & & & 46 & 38 \\
\hline Miscarriage/intrauterine death & 285 & 284 & 13 & 19 & 96 & 106 & 26 & 24 \\
\hline Abortion for malformation & 11 & & & & & & $2^{\star}$ & $2^{\star}$ \\
\hline Deliveriest & 4389 & 4347 & 502 & 482 & 2430 & 2442 & $376^{\star}$ & $394^{\star}$ \\
\hline Twin babies & 72 & 76 & 12 & 8 & $51 \ddagger$ & 40 & 4 & 14 \\
\hline Perinatal deaths & 20 & 39 & 5 & 5 & 12 & 12 & 2 & 4 \\
\hline Live births $₫$ & 4334 & 4272 & 491 & 474 & 2370 & 2390 & 372 & 383 \\
\hline Low Apgar score ( $<7$ at 1 & & & & & & & & \\
\hline minute) & 286 & 276 & 34 & 23 & $199^{\star}$ & $201^{\star}$ & 36 & 28 \\
\hline Induced labour & $594^{\star}$ & $569^{\star}$ & 32 & 38 & 140 & 218 & 28 & 31 \\
\hline
\end{tabular}

criterion and because study results were never published in detail was not included..$^{23}$ Thus, four studies qualified for the present analysis. ${ }^{24-26}$

All trials compared routine with selective ultrasound. The fetal anatomical reference measurement for gestational age was the biparietal diameter in three studies $^{72425}$ and the rump length in one study. ${ }^{26}$ In all four trials randomisation achieved comparable study and control groups in terms of maternal age, parity, marital and socioeconomic state, and smoking.

Size of study groups, recruiting of subjects, and ultrasonography schedules are summarised in table I. Altogether 15153 pregnancies were included in the four trials (7992 cases and 7943 controls). Twin pregnancies were included in the analysis and regarded as multiple events in terms of delivery, perinatal mortality, and Apgar score but as one case in terms of pregnancy and live birth rate. The latter may slightly bias the result because it is believed that routine ultrasound scanning may be especially helpful in multiple pregnancies. Counting multiple pregnancies as multiple births for the live birth rate, however, did not change the results (data not shown). We present figures according to one multiple pregnancy $=$ one delivery $=$ one birth because a live birth rate based on the count of multiple births per one randomised pregnancy would make the rate somewhat illogical as it could exceed $100 \%$. An exclusion of twin pregnancies altogether did not change the result. A separate analysis of twins comprised too few cases to allow meaningful statistical analysis (data not shown).

The trials conducted in Helsinki ${ }^{24}$ and Trondheim ${ }^{25}$ randomised all women on the diagnosis of pregnancy, whereas in the Stockholm ${ }^{7}$ and Missouri ${ }^{26}$ studies only those pregnant women who had no clinical indication for ultrasound scanning at their first antenatal visit or at 12 weeks' gestation were included. The latter study design may therefore have resulted in a selection of a study group at a comparatively lower risk of complications. Our analysis, however, did not yield any heterogeneity in the results between the studies with these different methods in selection of patients (see table III).

\section{DATA ANALYSES}

The following outcome variables were analysed: live birth rate, perinatal mortality, proportion of babies with Apgar score $<7$ at 1 minute, and rate of induced labour. For each trial $2 \times 2$ contingency tables were constructed by using the number of randomised pregnancies and live births (live birth rate) and the number of perinatal deaths and deliveries (perinatal mortality) in both screening and control groups. Tables were similarly constructed for the Apgar score at 1 minute and the number of induced labours. The live birth rate was analysed on an intention to screen basis (live births per randomised pregnancies). A separate analysis of a live birth rate per pregnancies available for analysis (excluding women who failed to complete the study, had a legal abortion, or who were not pregnant or refused) was not different from the intention to treat analysis (data not shown).

The resulting $2 \times 2$ tables were combined according to the Mantel-Haenszel procedure. ${ }^{27}$ Summary odds ratio are reported with $95 \%$ confidence intervals. The $\chi^{2}$ test for heterogeneity was calculated for each variable to control the consistency of the effects of ultrasound scanning across the four studies.

\section{Results}

Table II shows the results of the four randomised trials with the number lost to follow up and events associated with the loss of pregnancies. The summary estimates of the live birth rate, perinatal mortality, and 
TABLE III-Meta-analysis of outcome of pregnancy in randomised controlled trials of routine versus selective ultrasound scanning

\begin{tabular}{|c|c|c|c|c|c|c|c|c|c|c|c|c|c|c|c|}
\hline \multirow[b]{2}{*}{ Trial } & \multicolumn{3}{|c|}{$\begin{array}{c}\text { Miscarriages } / 1000 \\
\text { randomised pregnancies }\end{array}$} & \multicolumn{3}{|c|}{$\begin{array}{l}\text { Perinatal mortality/1000 } \\
\text { deliveries }\end{array}$} & \multicolumn{3}{|c|}{$\begin{array}{l}\text { Live birth rate }{ }^{\star} / 1000 \\
\text { randomised pregnancies }\end{array}$} & \multicolumn{3}{|c|}{$\begin{array}{l}\text { Low Apgar score }(<7 \text { at } \\
1 \text { minute }) / 1000 \text { deliveries }\end{array}$} & \multicolumn{3}{|c|}{$\begin{array}{l}\text { Induced labours } / 1000 \\
\text { randomised pregnancies }\end{array}$} \\
\hline & Cases & Controls & $\begin{array}{c}\text { Odds ratio } \\
\text { (95\% confidence } \\
\text { interval) } \\
\end{array}$ & Cases & Controls & $\begin{array}{c}\text { Odds ratio } \\
\text { (95\% confidence } \\
\text { interval) } \\
\end{array}$ & Cases & Controls & $\begin{array}{c}\text { Relative risk } \\
(95 \% \text { confidence } \\
\text { interval }) \dagger\end{array}$ & Cases & Controls & $\begin{array}{c}\text { Odds ratio } \\
\text { (95\% confidence } \\
\text { interval) }\end{array}$ & Cases & Controls & $\begin{array}{c}\text { Odds ratio } \\
\text { (95\% confidence } \\
\text { interval) }\end{array}$ \\
\hline Helsinki ${ }^{2+}$ & $6 \cdot 1$ & $6 \cdot 1$ & $0.99(0.83$ to 1.17$)$ & $4 \cdot 6$ & $9 \cdot 0$ & $0.51(0.29$ to 0.87$)$ & 924 & 925 & $0.99(0.99$ to 1.01$)$ & $6 \cdot 6$ & $6 \cdot 4$ & $1.02(0.86$ to 1.22$)$ & 141 & 138 & $1.02(0.90$ to 1.15$)$ \\
\hline Trondheim" & 2.5 & $3 \cdot 8$ & $0.66(0.32$ to 1.35$)$ & $10 \cdot 0$ & $10 \cdot 5$ & $0.95(0.27$ to 3.31$)$ & 963 & 950 & $1.01(0.99$ to 1.04$)$ & $6 \cdot 8$ & $4 \cdot 8$ & $1.46(0.84$ to 2.51$)$ & 64 & 79 & $0.81(0.48$ to 1.35$)$ \\
\hline Stockholm & 3.9 & $4 \cdot 2$ & $0.91(0.69$ to 1.21$)$ & $4 \cdot 9$ & 4.9 & $1.00(0.45$ to 2.24$)$ & 955 & 952 & $1.00(0.99$ to 1.02$)$ & $8 \cdot 4 \ddagger$ & $8 \cdot 4 \ddagger$ & $1.00(0.82$ to 1.23$)$ & 59 & 91 & $0.64(0.51$ to 0.81$)$ \\
\hline Missouri & $5 \cdot 7$ & $5 \cdot 3$ & $1.08(0.61$ to 1.91$)$ & $5 \cdot 3$ & $10 \cdot 2$ & $0.52 p=0.36 \$$ & 811 & 840 & $0.97(0.91$ to 1.02$)$ & $9 \cdot 6$ & $7 \cdot 2$ & $1.37(0.82$ to 2.29$)$ & 70 & 75 & $0.88(0.53$ to 1.60$)$ \\
\hline Pooled estimatef & & & $0.96(0.84$ to $1 \cdot 10)$ & & & $0.64(0.43$ to 0.97$)$ & & & $0.99(0.88$ to 1.12$)$ & & & $1.05(0.93$ to 1.19$)$ & & & $0.91(0.82$ to 1.01$)$ \\
\hline Test for heterogeneity & & & $p>0.50$ & & & $p>0.50$ & & & $p=0.45$ & & & $p=0.46$ & & & $p=0.005$ \\
\hline
\end{tabular}

rate of miscarriage in the four trials are given in table III and the figure. The perinatal mortality showed a significant overall reduction in the screened groups (odds ratio $=0.64 ; 95 \%$ confidence interval 0.43 to 0.97 ), whereas the live birth rate was identical in the two groups $(0 \cdot 99 ; 0 \cdot 88$ to $1 \cdot 12)$.

The significant reduction of perinatal mortality in the screening group (table II) is due mainly to the contribution of the Helsinki trial ${ }^{24}$ (though the $\chi^{2}$ test for heterogeneity showed no significantly different reduction across the four trials $(p=0 \cdot 59)$. Table II also shows that this reduction in the Helsinki trial was mostly the result of induced abortion of malformed fetuses, that the live birth rate is determined mainly by miscarriages and other events before delivery, and that perinatal deaths alone have a rather negligible impact on the overall number of unsuccessful pregnancies. Evidently the live birth rate is a measure of the overall success of pregnancy, to which complications during delivery contribute only little. Perinatal morbidity as estimated by the proportion of Apgar scores $<7$ at 1 minute was not different between women with routine ultrasound scanning and selective ultrasound scanning $(1.05 ; 0.93$ to 1.19$)$. The number of induced labours was significantly lower in the screened group in one trial.' This result, however, is at variance with the observation of no such difference in the other three trials (table III).

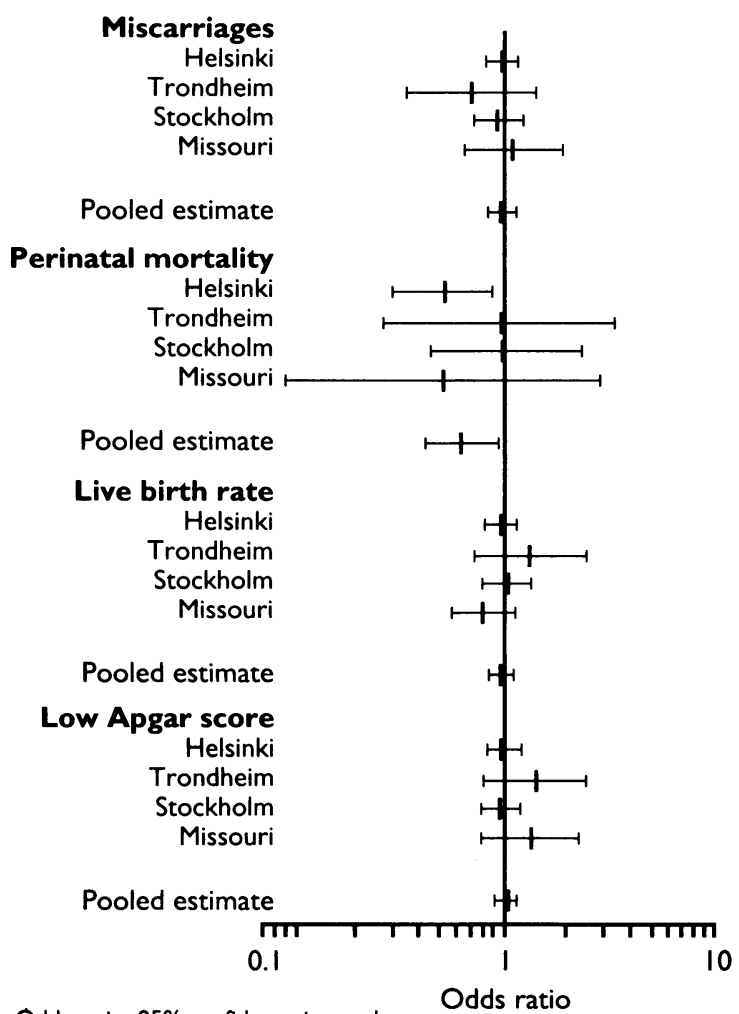

Odds ratio, $95 \%$ confidence intervals

Meta-analysis of outcome of pregnancy in randomised controlled trials of routine versus selective ultrasound scanning in pregnancy

\section{Discussion}

Authors of over 100 studies that evaluated the use of ultrasonography in obstetrics claimed a benefit of routine scanning..$^{20}$ Our meta-analysis of randomised controlled trials shows no evidence that routine ultrasound scanning in pregnancy improves the outcome. Although ultrasonography offers the benefit of a fairly precise dating of gestational age and the early detection of fetal growth retardation and malformations, it does not result in an increase in the number of live births or a decrease in perinatal morbidity as measured by Apgar score. The number of induced labours in the ultrasound group was significantly lower in the Stockholm trial $^{7}$ as a result of the more accurate dating of the gestational age but this trial is at variance with the three others. This may suggest that the rate of induced labour is more a function of local obstetric policies than a true benefit of ultrasound screening. We conclude that the combined evidence of randomised controlled trials shows no change in the outcome of pregnancy whether routine ultrasound scanning is performed or not.

The fact that the same trials show a significant overall reduction of the perinatal mortality through routine ultrasound scanning is consistent with a selection bias in the presence of ultrasonography. The significant reduction of the perinatal mortality can therefore be interpreted as a statistical artefact. This is produced by the antenatal loss of fetuses through early termination of pregnancy because of sonographically detected malformations. Malformations are a major contributor to perinatal mortality. In the absence of ultrasonography the delivery of such a malformed fetus may therefore be associated with perinatal death. The loss of fetuses through induced abortions after ultrasound scanning may decrease the number of perinatal deaths without improving the eventual outcome of pregnancy-that is, the number of live births.

LIVE BIRTH RATE AS MEASURE OF PREGNANCY OUTCOME

We propose the live birth rate as a new measure of pregnancy outcome that is unbiased by a possible selective loss of pregnancies before delivery. It seems more meaningful to assess how many pregnancies led to successful delivery of a live baby than to consider only perinatal mortality, which ignores the success of the pregnancy before delivery. Nevertheless, the live birth rate cannot be regarded as an unbiased substitute for the conventional perinatal mortality. The live birth rate is an overall measure of pregnancy outcome which incorporates miscarriages and abortion as well as perinatal deaths and thus all failures of pregnancy combined. It could therefore be biased by an unequal distribution of risk factors for miscarriage such as maternal age, smoking, or parity between study and control group. In all four trials included in this metaanalysis this was not the case.

An even more precise and meaningful measure of pregnancy outcome may be a healthy live birth rate (birth of a healthy baby could be defined as a normal 
state of health one week or perhaps one month after birth). We could not, however, include the healthy live birth rate in our analysis because the necessary data were not available.

We conclude that studies and meta-analyses about the effectiveness of routine ultrasound in pregnancy have not sufficiently dealt with the problems inherent in the various outcome measures. We therefore suggest that the live birth rate as an overall estimate of pregnancy outcome should be integrated into the future evaluative research of routine ultrasound scanning in pregnancy.

The use of ultrasonography in the control groups (see table I) may have diluted a possible true effect of ultrasound screening. This seems unlikely, however, given that this statistically powerful meta-analysis could not show an improvement in the live birth rate and that the lack of improvement of the live birth rate was consistent and unrelated to the varying frequency of selective ultrasound scanning in the control groups. As there is no direct evidence that ultrasound scanning may improve the outcome of pregnancy future trials should be conducted with control groups in which ultrasound is performed more selectively. Research efforts should be dedicated to identifying clinical conditions for which selective ultrasonography in pregnancy is truly beneficial. Ultrasonography seems helpful in cases such as unclear vaginal bleeding but the available evidence does not support the notion that the ultrasonographical monitoring of growth retardation is able to improve the outcome..$^{1314}$

DOES ROUTINE ULTRASOUND SCANNING HAVE ADVERSE EFFECTS?

Ultrasound screening may have additional subtle adverse effects which may cause a loss of pregnancies beyond the increase of induced abortions. The increase in the detection and labelling of complications such as malformations and growth retardation, sometimes falsely due to unavoidable false positive results, may adversely affect the pregnant woman and increase the rate of miscarriage. If, on the contrary, routine ultrasound decreases the number of miscarriages through an early detection of growth retardation for example, this would also affect the live birth rate. The results of our meta-analysis do not support either hypothesis (see table II). This consideration, nevertheless, may further establish the necessity of a measure that reflects the success of the entire pregnancy (that is, live births) and not only the success of delivery (that is, perinatal mortality) in comparing the effects of screening on outcome of pregnancy.

The Helsinki trial was the only trial with a specific intent of screening for malformations.$^{24}$ In this trial $2 \cdot 4$ per 1000 pregnant women in the screening group were unnecessarily disturbed by a false diagnosis of a malformed fetus, which turned out to be normal (in comparison, 2.7 per 1000 pregnant women were preserved from delivering a malformed baby). Ultrasonography, like any other test, is not free of errors, and this matters especially in the context of screening. Though routine ultrasound scanning does not improve the outcome of pregnancy, it exposes pregnant women to the risk of false diagnosis of malformations. With growing practical experience this problem may perhaps become smaller, ${ }^{10}$ but outside the context of clinical studies overdiagnosis of malformations may well be more important.

The detection of severe malformations through ultrasonography may be sufficient reason to justify its general use. Improved skills of examiners and improved technical quality of ultrasound scanners may make screening even more effective in detecting fetal abnormalities even in a low risk population,,$^{1028}$ and in some instances this may avoid late clinical presentation

\section{Clinical implications}

- Routine ultrasound scanning in pregnancy is effective in detecting fetal growth retardation, multiple pregnancies, and severe malformations

- This meta-analysis of randomised controlled trials shows that routine ultrasound scanning does not improve the outcome of pregnancy in terms of live birth rate and Apgar score

- Perinatal mortality is reduced because fetuses with severe malformations are aborted in an early stage of pregnancy rather than dying perinatally

- Routine ultrasound scanning in pregnancy is indicated only if explicitly performed to exclude congenital malformations

of malformations needing treatment. Whether and to what extent this will decrease infant morbidity and mortality, however, has not been shown.

For many women routine ultrasound scanning may be of considerable benefit by offering the option of an early abortion of a malformed baby and by reducing the concern of giving birth to a malformed baby. This value must be weighed against the risk of false positive diagnosis of malformations. To define the magnitude of such advantages and disadvantages, however, utility analyses may be needed.

Before such analysis is performed, we suggest that routine ultrasound scanning is useful if explicitly declared as a prenatal screening for malformations to which a pregnant woman would have to consent. This would require all efforts to minimise false positive diagnosis of malformations with the possibility of abortion of normal fetuses. If a woman does not consent to screening for malformations, however, routine ultrasound scanning is not indicated.

1 Royal College of Obstetricians and Gynaecologists Working Party. Routine ultrasound examination in pregnancy. London: Royal College of Obstetricians ultrasound examination in pregn

2 Hackelörer BJ. Die Rolle der Ultraschalldiagnostik bei der Erkennung fetaler Gefahrenzustände. $Z$ Geburtsch Perinat 1981;186:1 19-24.

3 Blondel $B$, Ringa V, Breart $G$. The use of ultrasound examination, intrapartum fetal heart rate monitoring and betamimetic drugs in France. $\mathrm{Br} f$ Obstet Gynaecol 1989;96:44-51

4 US Preventive Services Task Force. Guide to clinical preventive services. Baltimore: Williams and Wilkins, 1989.

5 Campell S, Warsof SL, Little D, Cooper DJ. Routine ultrasound screening for the prediction of gestational age. Obstet Gynecol 1985;65:613-20.

6 Persson PH, Kullander S. Long-term experience of general ultrasound screening in pregnancy. Am $\mathcal{F}$ Obstet Gynecol 1983;146:942-7.

7 Waldenström U, Axelsson $\mathrm{O}$, Nilsson S, Eklund G, Fall $\mathrm{O}$, Lindenberg S, et al. Effects of routine one-stage ultrasound screening in pregnancy: a randomised controlled trial. Lancet 1988;ii:385-8.

8 Mintz MC, Landon MB. Sonographic diagnosis of fetal growth disorders. Clin Obstet Gynecol 1988;31:44-52.

9 Grennert L, Persson PH, Gennser G: Benefits of ultrasonic screening of a pregnant population. Acta Obstet Gymecol Scan Suppl 1978;78:5-14.

10 Chitty LS, Hunt GH, Moore J, Lobb MO. Effectiveness of routine ultrasonography in detecting fetal structural abnormalities in a low risk population. BMF 1991;303:1165-9.

11 Simpson GF, Creasy RK. Obstetric management of the growth retarded baby. Clin Obstet Gynecol 1984;11:481-97.

12 Laurin J, Persson PH. The effect of bedrest in hospital on fetal outcome in pregnancies complicated by intra-uterine growth retardation. Acta Obstet Gynecol Scand 1987;66:407-11.

13 Larson T, Falck Larson J, Petersen S, Greisen G. Detection of small-forgestational-age fetuses by ultrasound screening in a high risk population: a gestational-age fetuses by ultrasound screening in a high risk popula

14 Secher NJ, Kern Hansen P, Lenstrup C, Sindberg-Eriksen P, Morsing G. A randomized study of fetal abdominal diameter and fetal weight estimation for detection of light-for-gestation infants in low-risk pregnancies. Br Y Obstet Gynaecol 1987;94:105-9.

15 Saunders N, Paterson C. Effect of gestational age on obstetric performance: when is "term" over? Lancet 1991;338:1190-2.

16 Crowley P. Elective induction of labour at $41+$ weeks gestation. In: Chalmers I, ed. Oxford database of perinatal trials. Oxford: Oxford University Press, 1991. (Version 1.2, disk issue 5; record 4144.)

17 Hannah ME, Hannah WJ, Hellmann J, Hewson S, Milner R, Willan A, and the Canadian Multicenter Post-term Pregnancy Trial Group. Induction of the Can compared with serial antenatal monitoring in post-term pregnancy. N Engl I Med 1992;326:1587-92.

18 Thompson SG, Pocock SJ. Can meta-analysis be trusted? Lancet 1991;338: 1127-30. 
19 Neilson JP. Routine ultrasound in early pregnancy. In: Chalmers I, ed. Oxford database of perinatal trials. Oxford: University Press, 1991. (Version 1,2, disk issue 6 , record 3872 .)

20 Ringa V, Blondel B, Breart G. Ultrasound in obstetrics: Do the published evaluative studies justify its routine use? Int $\mathcal{f}$ Epidemiol 1989;18:489-97.

21 Bennett MJ, Little G, Dewhurst J, Chamberlain G. Predictive value of ultrasound measurement in early pregnancy: a randomised controlled trial. Br f Obstet Gynaecol 1982;89:338-41.

22 Neilson JP, Munjanja SP, Whitfield CR. Screening for small for dates fetuses: a controlled trial. $B M 7$ 7 1984;289:1179-82.

23 Eik Nes SH, Okland O, Aure JCh, Ulstein M. Ultrasound screening in pregnancy: a randomsied controlled trial. Lancet 1984;i:1347.

24 Saari-Kemppainen A, Karjalainen O, Ylöstalo P, Heinonen OP. Ultrasound screening and perinatal mortality: controlled trial of systematic one-stag screening in pregnancy. The Helsinki Ultrasound Trial. Lancet 1990;336: 387-91.

25 Bakketeig LS, Eik Nes SH, Jacobsen G, Ulstein GK, Brodtkorb CJ, Balstad P, et al. Randomised controlled trial of ultrasonographic screening in pregnancy. Lancet 1984;ii:207-11.

26 Ewigman B, LeFevre $M$, Hesser J. A randomized trial of routine prenatal ultrasound. Obstet Gynecol 1990;76:1 189-94.

27 Mantel N, Haenszel W. Statistical aspects of the analysis of data from retrospective studies of disease. 7 Natl Cancer Inst 1959;22:719-48.

28 Luck CL. Value of routine ultrasound scanning at 19 weeks: a four year study of 8849 deliveries. $B M \mathcal{F} 1992 ; 304: 1474-8$.

(Accepted 21 April 1993)

\title{
Breast feeding and risk of breast cancer in young women
}

\author{
United Kingdom National Case-Control Study Group
}

\begin{abstract}
Objective-To investigate whether breast feeding is related to subsequent risk of breast cancer.

Design-Population based case-control study designed primarily to investigate the relation between oral contraceptives and risk of breast cancer; data obtained from questionnaires administered by interviewers, general practitioner notes, and family planning clinic records.

Setting-11 health regions in Britain.

Subjects-Women diagnosed with breast cancer before age 36 living in the defined study areas. One control per case, matched for age, was selected from the list of the case's general practitioner. 755 case-control pairs were interviewed.
\end{abstract}

Main outcome measures-Duration of breast feeding each liveborn infant; timing of return of menses; hormone use; other risk factors for breast cancer.

Results-Risk of breast cancer fell with increasing duration of breast feeding (relative risk $=0.94$ per three months' breast feeding; test for trend $p=0.026$ ) and with number of babies breast fed (relative risk $=0 \cdot 86$; test for trend, $p=0 \cdot 017$ ). Breast feeding each baby for longer than three months conferred no additional benefit. Breast feeding was more strongly negatively associated with risk of breast cancer than duration of postpartum amenorrhoea $\left(\chi^{2}\right.$ test for trend, $\left.p=0 \cdot 69\right)$. Hormonal suppression of lactation was unrelated to risk of breast cancer (relative risk $=0.96$ per episode of suppressed lactation; test for trend, $p=0 \cdot 72$ ).

Conclusions-These results suggest that breast feeding protects against the development of breast cancer in young women.

\section{Introduction}

The main results of our large case-control study of breast cancer in young women indicated an increased risk of breast cancer associated with increasing duration of use of combined type oral contraceptive. ${ }^{12}$ In the first report we noted in passing that breast feeding seemed to be associated with a significantly decreased risk of breast cancer. We report here our detailed findings on the relation between breast feeding and risk of breast cancer in these young women.

Professor C E D Chilvers,

Department of Public

Health Medicine and

Epidemiology, University of

Nottingham Medical

School, Nottingham

NG7 2UH.

BMF 1993;307:17-20 breast cancer was diagnosed before their 36th birthday. For every case, one control was chosen, effectively at random, from the list of that case's general practitioner.' The control's date of birth was matched to within six months of the date of birth of the case, and the control had to have been registered with the general practitioner before the date of diagnosis of the case. If a case could not be interviewed no attempt was made to interview her matched control. If the chosen control could not be interviewed a second (or further) control was selected in the same manner as the first. For both cases and controls the study was restricted to white women with no previous malignancy, severe learning disability, or psychiatric condition. The women were seen in their homes by trained interviewers between January 1984 and February 1988. Each case-control pair was interviewed by the same interviewer. A total of 1049 eligible cases were identified and $755(72 \%)$ were interviewed. Of the 755 first controls, $675(89 \%)$ were interviewed; the remaining 80 controls were replaced by second (68) or subsequent (12) choices.

Every control was given a pseudodiagnosis date, the date on which she was exactly the same age as her matching case was at diagnosis. The data analysed were restricted to events before the diagnosis or pseudodiagnosis date. Pregnancy and contraceptive histories were taken by constructing a calendar of events for each month from age 14 to diagnosis or pseudodiagnosis. After the interview data on obstetric and contraceptive history were abstracted from general practitioner notes by trained interviewers, and contraceptive information was also sought from any family planning clinic that the woman recalled attending. The data from all sources were used to construct a lifetime contraceptive calendar. We have not distinguished between brands of combined oral contraceptives or brands of progestogen-only pills. Twenty two women (12 cases, 10 controls) reported having used oral contraceptives but could not say which type; these women were assumed to have taken combined oral contraceptives.

For each recorded pregnancy resulting in a live birth the woman was asked whether she had breast fed the child. If she answered yes she was asked the duration of breast feeding and how long it was until she had her first period after delivery.

We have reported significant differences between cases and controls for several risk factors not related to parity-namely, age at menarche, family history of breast cancer, and a history of biopsy for benign breast disease. These three variables have been adjusted for in all adjusted relative risks in this report. Marital status, age at leaving school, weight, and alcohol consumption one year before diagnosis were similar in cases and 